\title{
DE UMA SEQUÊNCIA DIDÁTICA A CONSTRUÇÃO DE UM JOGO EDUCACIONAL DIGITAL: FAZENDINHA MATEMÁTICA
}

\author{
DE UNA SECUENCIA DIDÁCTICA A LA CONSTRUCCIÓN DE UNO \\ JUEGO EDUCATIVO DIGITAL: FAZENDINHA MATEMÁTICA
}

\author{
Gabriel Almeida Dias \\ Universidade Estadual do Sudoeste da Bahia,UESB, Brasil \\ dias.1618@gmail.com \\ Tânia Cristina Rocha Silva Gusmão \\ Universidade Estadual do Sudoeste da Bahia,UESB, Brasil \\ professorataniagusmao@gmail.com \\ Marlos Marques \\ Universidade Estadual do Sudoeste da Bahia,UESB, Brasil \\ marlos.uesb@gmail.com
}

\begin{abstract}
RESUMO
Este artigo apresenta uma versão beta de um jogo digital, produto gerado, por uma equipe de colaboradores que faz parte do projeto "Desenvolvimento e aplicação de videogames para potencializar o ensino e a aprendizagem da Matemática na Educação Básica" da Universidade Estadual do Sudoeste da Bahia (UESB). Concretamente, apresentamos um review de nossas ações e objetivos na tentativa de transformar uma sequência didática analógica em um jogo digital educacional. Essa experiência, unindo tecnologia e educação, está sendo bastante enriquecedora e tem revelado o potencial dos jogos eletrônicos para despertar interesses e aprendizagens.
\end{abstract}

Palavras-chave: Jogos digitais. Aprendizagem. Matemática. 


\begin{abstract}
RESUMEN
Este artículo presenta una versión beta de un juego digital, producto generado, por un equipo de colaboradores que hace parte del proyecto de investigación "Desarrollo y aplicación de videojuegos para potencializar la enseñanza y el aprendizaje de las Matemáticas en Primaria y Secundaria" de la Universidad Estadual do Sudoeste da Bahía (UESB). Concretamente, presentamos un review de nuestras acciones y objetivos en el intento de transformar una secuencia didáctica analógica en un juego digital educacional. Unir la tecnología y la educación es enriquecedor y un medio de revelar el potencial de los juegos electrónicos para despertar interés y aprendizajes.
\end{abstract}

Palabras-clave: Juegos digitales. Aprendizaje. Matemática.

\title{
1. Introdução e breve revisão teórica
}

Muito se tem discutido sobre os rumos da educação. Um dos problemas que vem marcando o século atual é o aumento do desinteresse do alunado para com os estudos e a falta de estratégias para se lidar com isso. As salas de aula possuem uma formatação que praticamente não se alterou desde o século XVI-XVII, quando Comênio instituiu sua escola universal em que o professor era o centro do estudo e do conhecimento e seu dever era transmitir esses conhecimentos para os alunos.

Comênio sugeriu uma escola única e universal. Seu método apresentou os passos necessários para ensinar e destacou a função do professor como controlador da aprendizagem e da ordem, atribuindo a ele o centro do processo de ensino, já que era o transmissor absoluto do conhecimento. As aulas expositivas funcionavam como métodos eficazes de ensino. O autor enfatizava os recursos de ensino, os meios para ensinar, pois assim as imagens, as gravuras e os objetos ficariam gravados nas lembranças. (LACANALLO et al, 2007, p. 5)

Não queremos com isso desconsiderar ou desmerecer a metodologia implementada naquele tempo, pois sabemos que as metodologias didáticas não podem ser analisadas sob um ponto de vista descontextualizado da História. Comênio, assim como os jesuítas, trouxeram

\begin{tabular}{l|l} 
Revista RBBA & Revista Binacional Brasil Argentina
\end{tabular} 
enormes contribuições em sua época, que nos trouxeram ao pensamento atual de educação (LACANALLO et al, 2007, p. 5).

Os jovens atuais (grupo principal, mas não único que se pensa ao falarmos de educação) são muito diferentes dos jovens do século passado bem como o mundo também é um lugar diferente. Vivemos hoje sob a Era da Informação Digital, em que temos praticamente todo o conhecimento armazenado em nossos computadores e celulares. Por exemplo, hoje qualquer criança no Brasil pode visitar a qualquer dia ou hora o Museu do Louvre na França e conhecer muitas de suas belas obras, por meio de um cenário virtual que reproduz fielmente o museu (LOUVRE, 2017). Além disso, técnicas de realidade virtual estão sendo cada vez mais utilizadas para melhorar a imersão, percepção e absorção desse grande volume de conhecimento. A informação está cada vez mais disseminada e globalizada como nunca antes havia ocorrido na história da humanidade.

Por conta disso temos os jovens de hoje designados como Nativos Digitais. Esse termo foi cunhado por Marc Prensky (2001) para se referir à nova geração nascida imersa em tecnologia, enquanto aqueles anteriores a essa geração são considerados como Imigrantes Digitais. Os Nativos Digitais processam múltiplas informações de forma paralela e mais rápida, além de possuir um comportamento ativo em relação ao novo, onde a exploração é parte fundamental no aprendizado e existe a necessidade de feedback imediato, entre outros (LEITE e MENDONÇA, 2013). Portanto, percebe-se que as práticas tradicionais de aprendizagem podem não surtir o mesmo efeito nessa geração, e é necessário mais uma vez romper com o modelo vigente em busca de novas metodologias que possam trazer um melhor aprendizado.

Os jogos digitais são uma nova classe de objetos de aprendizagem, servindo de ponte entre os alunos dessa nova geração e o conteúdo a ser estudado. Esses jogos têm em seu bojo uma gama de características que condizem com uma forma mais dinâmica de se aprender, onde o aluno é o protagonista de seu próprio aprendizado, seguindo seu próprio ritmo, e o mesmo o faz através de experimentação, de uma forma que a assimilação ocorra mais seguramente.

Os games respeitam os diferentes estilos de aprendizagem e com isso permitem uma maior aproximação entre conteúdo e alunos, principalmente por poder atender às principais características de aprendizagem dos nativos digitais, além de fazer parte do seu dia a dia 
e do seu mundo. (LEITE e MENDONÇA apud MATTAR, 2013, p. 134).

Outro ponto que se deve observar é que os jogos não têm a premissa de substituir os professores. Muitos desses parecem temer uma possível retirada de toda a orientação que é passada pelos educadores, e colocar apenas jogos (e outras tecnologias) no lugar. Porém é exatamente o oposto disso. Os games são ferramentas e meios, para que o docente tenha um maior leque de alternativas para poder auxiliar o aprendente em sua performance educativa. A utilização desta nova tecnologia mudou o papel do educador, que deixa de ser o transmissor e fonte de conhecimento para servir como mediador deste, trabalhando junto com os alunos (LEITE e MENDONÇA, 2013, p. 137).

Os Jogos Eletrônicos (JEs) e a educação possuem uma estreita relação entre si, e Bomfoco apud Gee (2012) aponta dois pontos importantes nesta sinergia. O primeiro é que os JEs ensinam algo e o jogador está sempre apto a aprender enquanto joga, pois este tipo de jogo possui bons princípios de aprendizagem, nos quais pode-se ressaltar:

- Interação: os JEs necessitam da interação do jogador para o seu desenvolvimento e a partir dela recebe feedback e novos desafios;

- Riscos: ao errar, é possível ao jogador retornar ao último ponto salvo, e a partir dos seus erros, refletir e criar novas estratégias para vencer o desafio;

- Boa coordenação dos problemas: os JEs colocam os objetivos mais fáceis anteriormente aos mais difíceis, facilitando assim a solução dos últimos;

- Frustração prazerosa: devido aos princípios acima, os JEs são considerados desafiadores já que os desafios situam-se dentro do regime de competência do jogador, o que os tornam motivadores;

- Sentidos contextualizados: os JEs sempre contextualizam as palavras nele veiculadas com ações, imagens e diálogos a elas relacionadas;

- Pensamento sistêmico: os JEs incentivam os jogadores a pensar sobre as relações entre os eventos, os fatos e as habilidades neles existentes;

- Explorar, pensar lateralmente e repensar os objetivos: os JEs incentivam os jogadores a explorar o jogo detalhadamente antes de seguirem em direção ao próximo desafio, esse pensamento lateral auxilia a repensar os objetivos do JE.

O segundo ponto importante é que a prática dos JEs proporciona experiências enriquecedoras e que posteriormente podem ser úteis de alguma forma aos jogadores, o que contraria a ideia de que esses jogos são apenas uma forma de lazer cuja prática não traria benefícios aos jogadores em suas outras áreas de atuação (BOMFOCO, 2012, p. 6). 
Logo percebemos que os jogos eletrônicos são potenciais ferramentas de educação, podendo ser usados para acrescer a experiência educativa dos novos aprendentes visto a familiaridade dos mesmos com este recurso, trabalhando diversos conteúdos de forma interdisciplinar e promovendo uma educação de qualidade e atrativa ao mesmo tempo. Nesse contexto, objetivamos com esse artigo apresentar as etapas de desenvolvimento de um jogo digital baseado em uma sequência didática analógica intitulada Fazendinha Matemática (GUSMÃO e MOURA, 2015) que trabalha com as operações fundamentais da matemática.

A sequência Fazendinha foi pensada para que os jogadores tenham uma noção mais clara de como funciona as operações matemáticas e como funciona o valor posicional dos números (DIAS e GUSMÃO, 2015, p. 10).

Embasados nos estudos sobre Sequência Didáticas de Brousseau (1986) Costa e Peretti (2013) define:

A sequência didática é um conjunto de atividades ligadas entre si, planejadas para ensinar um conteúdo, etapa por etapa, organizadas de acordo com os objetivos que o professor quer alcançar para a aprendizagem de seus alunos e envolvendo atividades de avaliação que pode levar dias, semanas ou durante o ano. É uma maneira de encaixar os conteúdos a um tema e por sua vez a outro tornando o conhecimento lógico ao trabalho pedagógico envolvido. (COSTA; PERETTI, 2013, p. 6).

A sequência Fazendinha é composta por um conjunto de atividades pensadas e desenhadas para estudantes e professores, cujo objetivo é o de desenvolver e avaliar destrezas cognitivas e metacognitivas em relação a um determinado conteúdo matemático, por meio da aprendizagem significativa de conceitos e do desenvolvimento da aprendizagem científica (GUSMÃO, 2014, p.175). Aliar a sequência didática a recursos eletrônicos pode trazer um diferencial na forma de apresentar a matemática e suscitar nos alunos a imaginação, a criatividade e o desejo pela aprendizagem.

A seguir, detalharemos os materiais e métodos utilizados para transformar a sequência Fazendinha Matemática em um jogo digital, seguido de explicação detalhada das principais partes do jogo, detalhando a interação do aluno com os objetivos da sequência didática. 


\section{Materiais e métodos na produção de um jogo digital}

Com base em elementos de estudos da área de jogos educacionais, pretendemos adaptar uma sequência analógica a um novo ambiente. Os estudos em jogos educacionais se diferenciam dos jogos comuns por conta do objetivo primário de um jogo educacional que deve ser voltado para trabalhar conteúdos, garantir o aprendizado nesses conteúdos e disponibilizar ferramentas de acompanhamento do progresso do jogador em relação à sua aprendizagem. Para isso é necessária a criação de alguns recursos e a adaptação de outros, fazendo um equilíbrio entre o foco educacional e o aspecto lúdico, que não pode se perder, com risco de tornar o jogo desinteressante.

Ao considerar esses aspectos, a equipe de elaboração do jogo aqui proposto conta com a colaboração de pessoas tanto da área educacional quanto da área técnica, trabalhando de forma conjunta para que o jogo possa ter um balanceamento adequado e não cair no que alerta Aranha (2006) sobre jogos feitos por técnicos tão somente, que se tornam muito atrativos e pouco pedagógicos, ou jogos feitos apenas por pedagogos, que apesar de terem uma carga de aprendizagem forte, são desinteressantes para a maioria do público.

A sequência Fazendinha Matemática conta a história de um vilarejo cercado de fazendas e serve para ambientar os participantes em um enredo. Esse vilarejo é destruído por uma ventania restando poucos animais e plantações. Com o intuito de reconstruir o local, um dos fazendeiros propõe um sistema de trocas de animais e produtos, cuja regra básica é: dois objetos de menor valor são trocados por um de maior valor. Essa regra em matemática seria o sistema binário. Faz parte dessa sequência, entre outras atividades, um jogo da memória, onde pares de carta representando pintinhos (animais de menor valor) são trocados ao final do jogo por outros animais/produtos (objetos de maior valor). Esse é o ponto fundamental de toda a imersividade da história e das atividades desenvolvidas pelas personagens. (DIAS; GUSMÃO; FREDINI; GUSMÃO, 2015, p. 4201).

Estamos produzindo um jogo virtual com base nessa sequência, porém, precisamos adaptar e acrescentar alguns pontos devido à mudança de mídia e de ambiente. Uma primeira versão, chamada versão beta resume a primeira fase do jogo, base do jogo analógico: a caça aos pintinhos, as trocas no mercado e as atividades de prática da mecânica do sistema binário, mas que em essência busca-se trabalhar com as operações fundamentais da matemática. Em outras palavras, o jogador deverá caçar os pintinhos para que possa ir ao mercado trocar com 
os outros fazendeiros, utilizando a regra "dois por um". A captura dos pintinhos é representada pelo jogo da memória, em que o jogador deverá, em um determinado tempo, encontrar o máximo de pares de pintinhos e então trocá-los, até chegar ao item de valor maior que é uma fazenda, cumprindo assim o objetivo dessa primeira fase.

No desenvolvimento deste jogo estamos levando em conta elementos visuais e sonoros. Utilizamos a história em quadrinhos como animação por essa ser uma mídia atraente aos jovens, servindo como primeiro contato de muitos no mundo da leitura. Os elementos visuais também possuem um tom leve e cheio de cores, e os elementos sonoros são agradáveis e alegres (Figura 1). A envolvência visual, sonora e narrativa são aspectos primordiais para a atratividade do jogo, constituindo na maioria das vezes, sua primeira finalidade (THALER e FIALHO, 2015, p. 227).

Em relação às características lúdicas podemos citar toda a apresentação dos elementos do jogo por meio de uma história, para que o jogador possa imergir e se sentir interessado por aquele mundo e seus desafios. Por imersão entendemos como algo que dá a sensação de estar cercado por outra realidade, tomando toda a nossa atenção, todo nosso aparato perceptual (FERREIRA e OLIVEIRA apud MURRAY, 2011, p. 2). O jogo da memória em si também é uma dessas características, porém resolvemos acrescentar mais alguns elementos para torná-lo mais interessante. Os pintinhos que poderão ser encontrados no jogo da memória serão de diversos tipos e poderão ser colecionados pelo jogador. Ele terá uma lista dos tipos de pintinho que conseguir capturar, sendo alguns inclusive considerados raros. E afim de deixar o jogo ainda mais desafiador, fixamos um tempo máximo para que o jogador possa manipular as cartas. Um alerta é mostrado nos cinco segundos finais. 


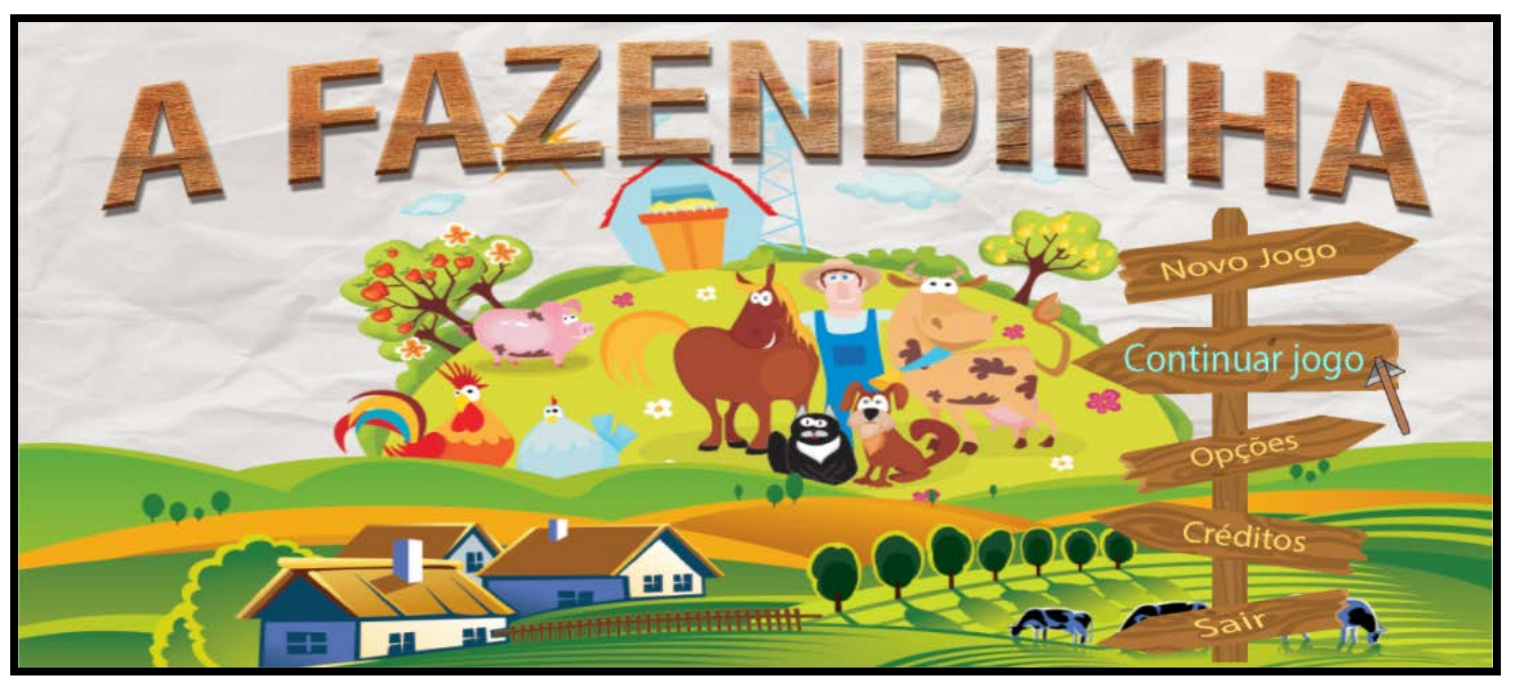

Figura 1 - Tela Inicial do jogo

O jogo da memória é uma das ações mais realizadas nessa primeira fase, versão beta (Figura 2). Essa tela do jogo possui poucos elementos: um ícone de saída, uma chamada de início, um relógio que marca o tempo para que o jogador possa encontrar os pares de cartas, e, naturalmente, as cartas com os pintinhos para que o jogador vire e consiga o par dos mesmos. As cartas sofrerão alterações conforme o jogador for subindo de nível para ir diversificando (aspecto lúdico) e aumentando o nível de dificuldade para que seja avaliado (aspecto educacional). Uma das alterações será o aumento de cartas conforme for aumentando de nível.

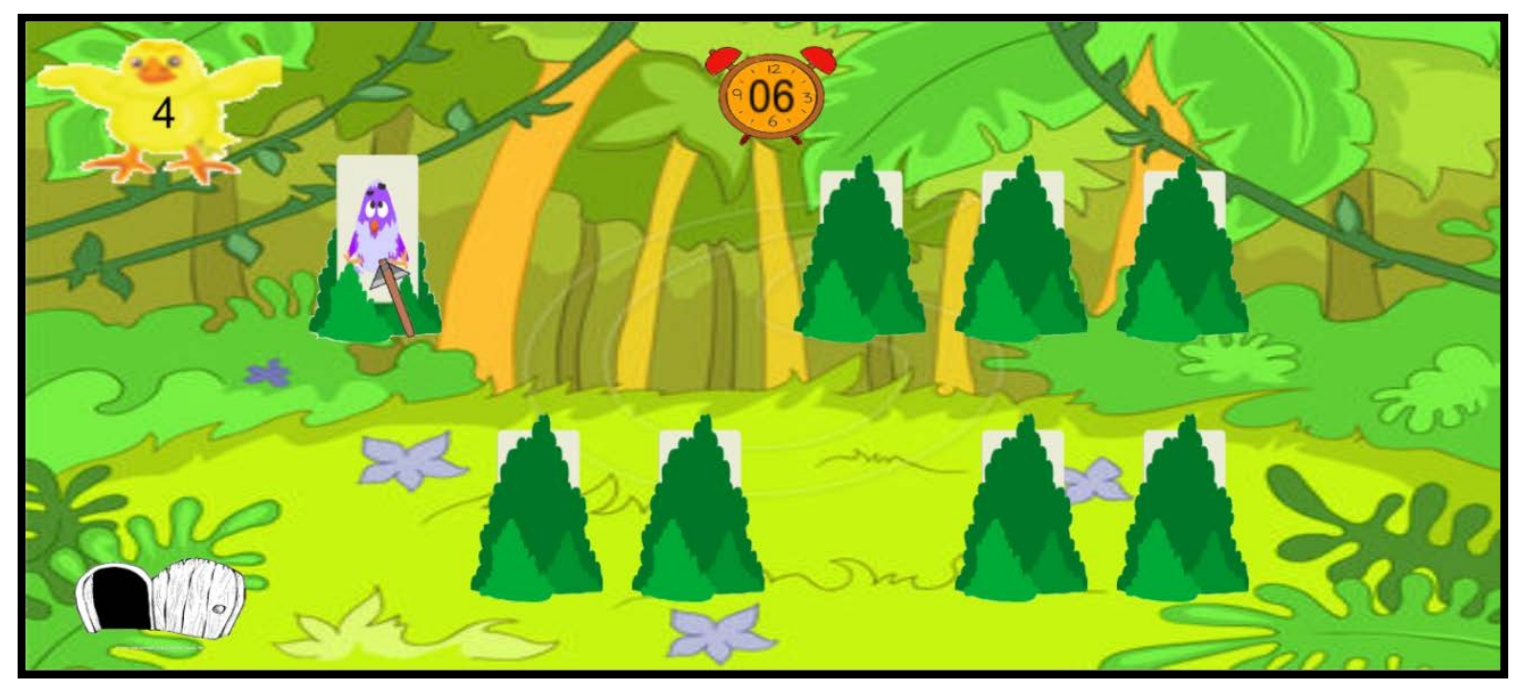

Figura 2 - Jogo da Memória

O mercado de trocas (Figura 3) acontece depois de cada partida do jogo da memória. O jogador deverá fazer as trocas com o objetivo principal de obter a fazenda (primeira fase) e 
de conhecer a mecânica de trocas. A tela tem um ícone de ajuda, para auxiliar o jogador e relembra-lo de seu progresso referente à tabela de trocas e uma lista de objetivos secundários que ele poderá acabar atingindo. Também possui um ícone de saída, e outro que o faz voltar à captura por mais pintinhos. Esse último ícone será configurado pelo professor, e poderá obrigar o jogador a fazer todas as trocas possíveis antes de realizar uma nova jogada.

Na parte superior da tela está uma barra de nível, que marcará o desempenho geral do jogador conforme ele for acertando as trocas, demonstrando em parte o seu entendimento da mecânica do jogo. Ao lado esquerdo se apresentam os animais que o jogador possui, e ao lado direito estão os fazendeiros com seus respectivos animais e mercadorias para que o mesmo possa trocar. As trocas normalmente serão feitas com dois itens: dois por um, porém o jogador também poderá escolher quatro itens e fazer as trocas: quatro por dois, não sendo possível mais que isso devido ao limite de espaço. O jogador também terá a possibilidade de fazer trocas inversas nessa primeira etapa, destrocando um item de maior valor por dois de menor valor. Inicialmente isso não terá sentido, porém ajudará o jogador a entender melhor o processo de troca bem como servirá para fases futuras onde ele necessitará de quantidades específicas de determinado item.

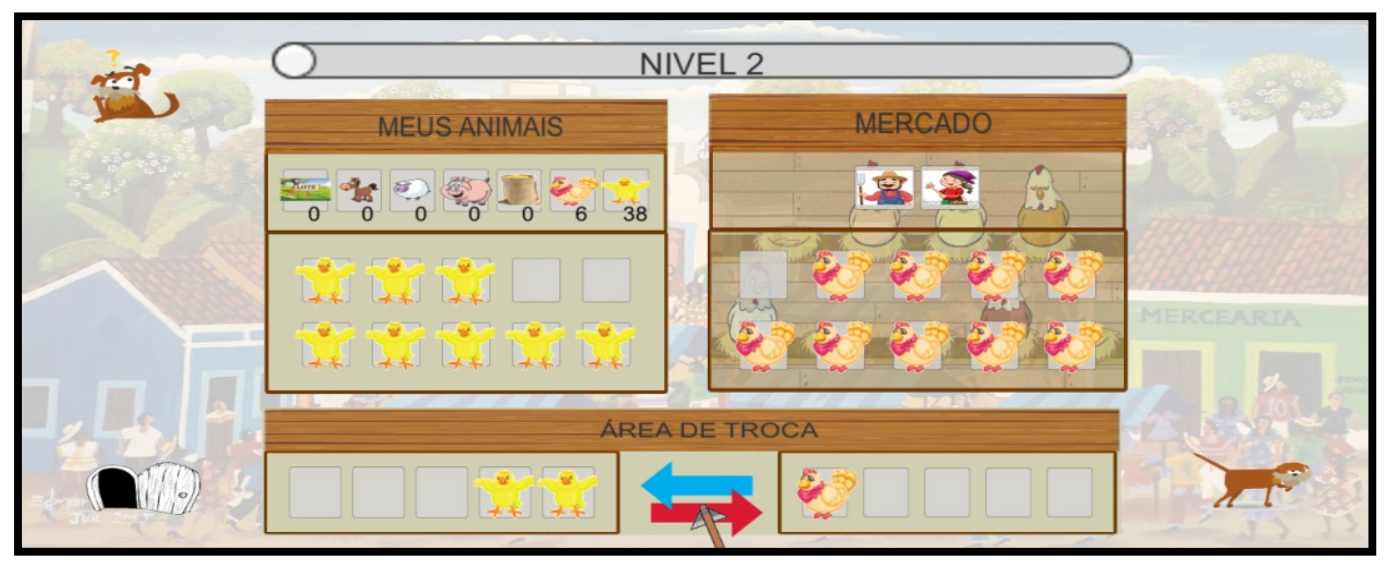

Figura 3 - Mercado de trocas

A cada passagem de nível o jogador será submetido a algumas atividades, que caso sejam resolvidas satisfatoriamente, o premiarão com uma pontuação à parte. Essas atividades condizem as que já existiam no jogo analógico e que servem para fixação das regras da tabela de troca e consequente aprendizagem matemática (Figura 4). 


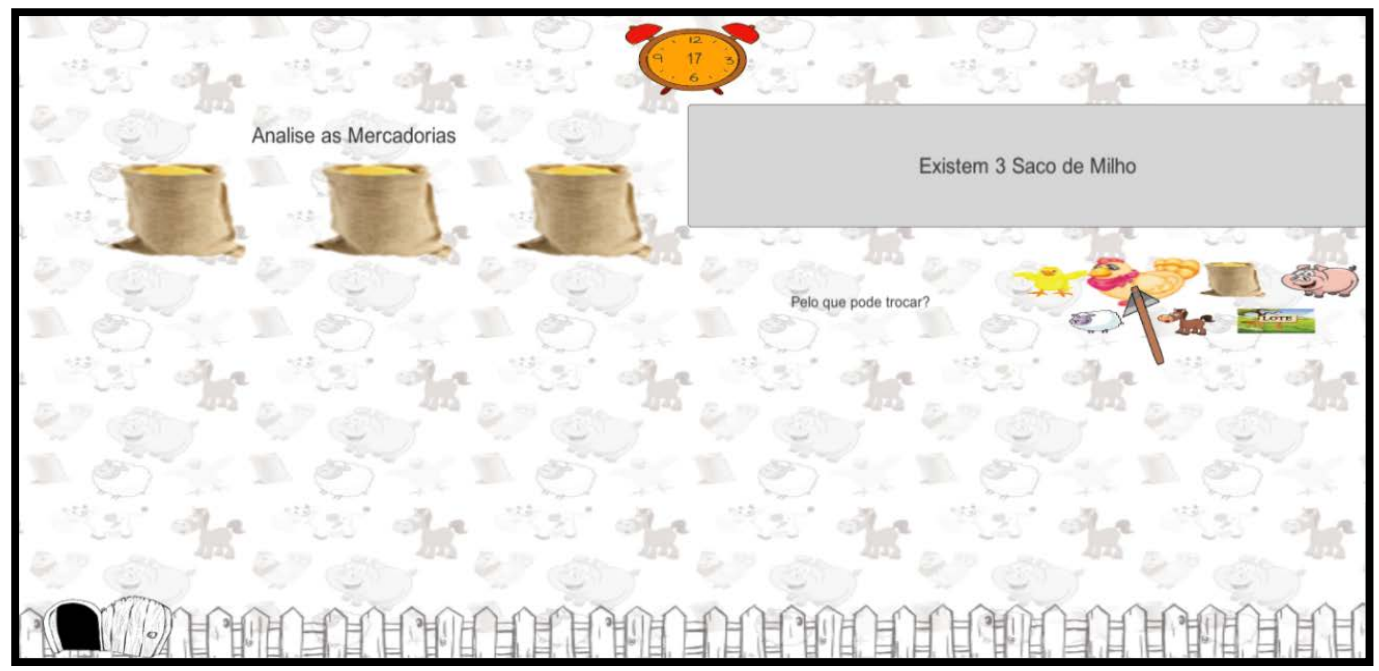

Figura 4 - Atividades

Além da captura (jogo da memória) e das trocas no mercado, o jogador contará também com uma tela principal do jogo, onde o mesmo poderá acessar as fases do jogo, as configurações, seu progresso, seus ganhos etc. (Figura 5). Inicialmente esta tela principal contará apenas a primeira fase do jogo.

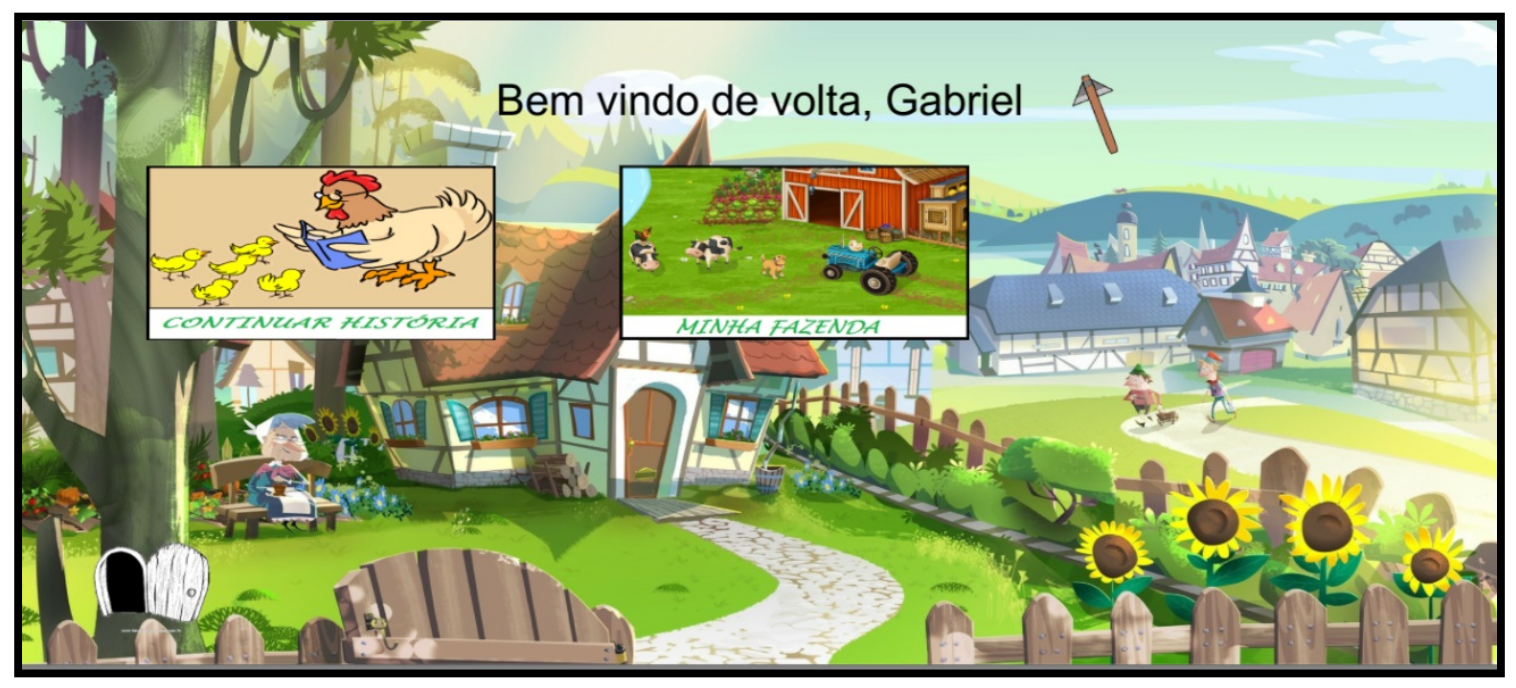

Figura 5 - Tela Principal

\section{Conclusão}

O jogo, embora ainda em desenvolvimento, passou por um pequeno teste com um grupo de três professoras da Educação Básica, trazendo elementos para ajustes do mesmo. Após esses primeiros ajustes, está pronto para ser testado com alunos e professores. A ideia é que esse público possa nos auxiliar a melhorar as características/elementos do mesmo, avaliando a história, as cores, as atividades etc. Tal ação, além de ir constituindo em um 
processo de validação de nosso trabalho, contribuirá para que possamos ajustar o jogo da melhor forma possível, fazendo com que a teoria esteja em concordância com a práxis.

O processo de virtualização dessa sequência didática tem nos trazido vários conhecimentos tanto da área pedagógica quanto de desenvolvimento de jogos, e percebemos com esse trabalho o quão intrínseco é a relação entre a experiência de jogar e de aprender, uma relação que não está sendo muito bem explorada pelas instituições de ensino.

Outros elementos do jogo virtual também possuem um caráter pedagógico, como a não inclusão de punições durante o jogo. A punição é muito utilizada em alguns títulos, porém vai de encontro às teorias de aprendizagem mais aceitas. Uma tela de configuração voltada especialmente ao professor está em desenvolvimento, com o objetivo de ajustar algumas ações e parâmetros do jogo, conforme o que ele esteja querendo passar para os alunos. Temos a intenção ainda de construir uma tela de acompanhamento e estatísticas, para que os professores possam observar o progresso do aluno, e assim trabalhar alguns pontos específicos para melhorar o aprendizado.

Pretendemos usar esse projeto como uma alavanca para outros trabalhos relacionados ao desenvolvimento de jogos educacionais visando, sobretudo, a troca de experiência e avanços nessa área.

\section{Referências}

BOMFOCO, M. A., \& AZEVEDO, V. de A. (2012). Os jogos eletrônicos e suas contribuições para a aprendizagem na visão de $\mathbf{J}$. P. Gee. Revista novas tecnologias na educação, 10 (3). Retrieved from http://seer.ufrgs.br/renote/article/view/36411.

BROUSSEAU, G. Fondements et Méthodes de la Didactique des Mathématiques. Recherches em Didactique des Mathématiques, Grenoble, v. 7, n. 2, p. 33-116, 1986.

COSTA, G. M. T.; PERETTI, L. Sequência didática na Matemática. REI. Revista de Educação do IDEAU, Getúlio Vargas, v. 8, p. 01-14, jan. 2013.

DIAS, G. A.; GUSMÃO, T. C. R. S.; FREDINI, P. S. R.; GUSMÃO, H. P. Fazendinha Matemática do jogo físico ao jogo virtual: Trabalhando as operações fundamentais da Matemática. In: Anais do XI nacional e IV Colóquio Internacional do Museu Pedagógico, 2015, Vitoria da Conquista. Crise, conflito e conhecimento no mundo contemporâneo, 2015.

DIAS, G. A; GUSMÃO, T. C. R. S. Virtualização da Sequência Fazendinha Matemática. Atas do $4^{\circ}$ SIPEMAT - Simpósio Internacional de Pesquisa em Educação Matemática, 29, 30 de junho e 01 de julho de 2015. Ilhéus, Bahia-Brasil, 2015. 
GUSMÃO, T. C.R.S. Desenvolvimento e aplicação de videogames para potencializar o ensino e a aprendizagem da Matemática na Educação Básica. Projeto de Pesquisa. UESB, 2014.

GUSMÃO, T.C.R.S.; MOURA, H. P.G. A Fazendinha Matemática: uma sequência didática (e de ensino) para trabalhar diferentes sistemas de numeração. Atas do $4^{\circ}$ SIPEMAT - Simpósio Internacional de Pesquisa em Educação Matemática 29, 30 de junho e 01 de julho de 2015. Ilhéus, Bahia-Brasil, 2015.

LEITE, P. S.; MENDONÇA, V. G. Diretrizes para Game Design de Jogos Educacionais. Proceedings of SBGames, p. 132-141, 2013.

LACANALLO, L. F. et al. Métodos de ensino e de aprendizagem: uma análise histórica e educacional do trabalho didático. In: Jornada do HISTEDBR, 7., 2007, Campo Grande. Anais... A organização do trabalho didático na História da Educação. Campo Grande: Editora Uniderp, 2007.

LOUVRE. Disponível em: <http://www.louvre.fr $\geq$. Acesso em 10 de mar. 2017.

PRENSKY, M, Digital Natives, Digital Immigrants. On the Horizon, 9 (5) 1-6, 2001.

MATTAR, J. Games em educação: como os nativos digitais aprendem. São Paulo: Pearson Prentice Hall, 2010.

THALER, A.; FIALHO, F. A. P.; O Design de Interação: Uma Abordagem para Jogos Educativos Centrados no Usuário, p. 223-230. São Paulo: Blucher, 2015.

\section{Sobre os autores}

Gabriel Almeida Dias. Graduando em Ciência da Computação pela Universidade Estadual do Sudoeste da Bahia, UESB. Grupo de pesquisa: Desenho de tarefas para o desenvolvimento de competências matemáticas no futuro professor dos Anos Iniciais da Educação Básica.

Tânia Cristina Rocha Silva Gusmão. Doutora em Didática das Ciências Experimentais pela USC Universidade de Santiago de CompostelaEspanha. Grupo de pesquisa: Desenho de tarefas para o desenvolvimento de competências matemáticas no futuro professor dos Anos Iniciais da Educação Básica.

Marlos Marques. Doutor em Engenharia de Computação pela Universidade Federal do Rio Grande do Norte - UFRN. Grupo de pesquisa: Desenho de tarefas para o desenvolvimento de competências matemáticas no futuro professor dos Anos Iniciais da Educação Básica. 